\title{
PITIOSE EQUINA: REVISÃO DE LITERATURA
}

\author{
Daniela Bortoli Becegatto \\ Marcelo de Souza Zanutto ${ }^{2}$ \\ Mauro José Lahm Cardoso ${ }^{3}$ \\ Augusto José Savioli de Almeida Sampaio ${ }^{4}$
}

BECEGATTO, D. B.; ZANUTTO, M. de S.; CARDOSO, M. J. L.; SAMPAIO, A. J. S. de A. Pitiose equina: revisão de literatura. Arq. Ciênc. Vet. Zool. UNIPAR, Umuarama, v. 20, n. 2, p. 87-92, abr./jun. 2017.

RESUMO: A pitiose é uma enfermidade que afeta diversas espécies animais, sendo a espécie equina geralmente a mais acometida. É causada por um oomiceto que se desenvolve principalmente em regiões subtropicais e tropicais em áreas alagadiças. As lesões frequentemente são únicas, bastante exsudativas, com prurido moderado a intenso e tendem a se localizar nas regiões do corpo que mais entram em contato com as áreas alagadas. Os meios de diagnostico e tratamento vêm sendo estudados surgindo assim cada vez mais técnicas e alternativas. Por ser uma doença que pode causar diversos impactos econômicos, seja por gastos com o tratamento ou até perda da função ou morte do animal, é uma doença que merece atenção no mercado de equinos no Brasil e no mundo. Este trabalho tem por objetivo abordar as principais características da pitiose, seu diagnóstico, tratamento e possíveis impactos.

PALAVRAS-CHAVE: Cavalo. Pitiose. Pythium insidiosum.

\section{EQUINE PHITYOSIS: LITERATURE REVIEW}

ABSTRACT: Pythiosis is a disorder affecting several animal species; equines are usually the most widely affected species. The disease is caused by oomycete mainly developed in swampy areas in tropical and subtropical regions. The lesions are frequently single, exudative wounds, with moderate to intense itching, with a tendency to be located in parts that are in contact with wetlands. Diagnostic and treatment procedures have been studied, resulting in increasingly techniques and alternatives. This condition causes several economic impacts, either by expenditure with treatment, loss of function or even death of the animal. Therefore, greater care in the equine market must be provided, both in Brazil and worldwide. This study aims to describe the main features of pythiosis, its diagnosis, treatment and possible impacts.

KEYWORDS: Horse. Pythiosis. Pythium insidiosum.

\section{PITIOSIS EQUINA: REVISIÓN DE LITERATURA}

RESUMEN: Pitiosis es una enfermedad que afecta a varias especies animales, siendo la espécie equina generalmente la más afectada. Es causada por un oomiceto que se desarrolla principalmente en las regiones tropicales y subtropicales en las zonas pantanosas. Las lesiones, con frecuencia son únicas, exudativas, con prurito moderado a intenso, y tienden a ubicarse en regiones del cuerpo que más entran en contacto com zonas húmedas. Los procedimientos de diagnóstico y tratamento vienen siendo estudiados, lo que resulta cada vez más en técnicas y alternativas. Por ser una enfermedad que puede causar varios impactos económicos, sea por gastos con el tratamiento, la pérdida de la función o la muerte del animal, es una enfermedad que merece atención en el mercado de equinos en Brasil y en el mundo. Este estudio há tenido como objetivo abordar las principales características de pitiosis, su diagnóstico, tratamiento y los posibles impactos.

PALAVRAS CLAVE: Caballo. Pitiosis. Pythium insidiosum.

Introdução

A pitiose, em conjunto com outras doenças piogranulomatosas, formam um complexo de doenças que são anatomopatologicamente semelhantes entre si, são afecções micóticas que acometem a pele, tecido subcutâneo, trato digestório e respiratório (BIAVA et al., 2007). Estas doenças podem afetar diversas espécies animais, incluindo caninos, bovinos e humanos, porém a espécie mais frequentemente afetada é a equina (SANTURIO et al., 2006a). O agente, Pythium insidiosum, um oomiceto característico de áreas tropicais, subtropicais e temperadas, possui como forma in- fectante o zoósporo que se desenvolve em temperaturas entre $30-40^{\circ} \mathrm{C}$ em áreas alagadiças (FREY JÚNIOR et al., 2007). Quando o animal que apresenta uma ferida entra em contato com água que contém o zoósporo ele pode ser infectado, esta infecção pode ocorrer não só na pele, mas também em outros sistemas. Não há predisposição para sexo, raça ou idade, e não existem relatos de transmissão animal-animal ou animal-humano (GAASTRA et al., 2010).

Nos equinos as lesões se localizam geralmente na porção distal dos membros, região ventral do abdômen ou ventral do tórax, devido ao maior contato destas partes com as áreas alagadiças. Essas lesões são geralmente únicas, no-

DOI: 10.25110 /arqvet.v20i2.2017.5974

${ }^{1}$ Discente Mestrado Profissional em Clínicas Veterinárias. Departamento de Clinicas Veterinárias, Universidade Estadual de Londrina (UEL), Londrina, Paraná, Brasil. E-mail: danibecegatto@gmail.com. *Autor para correspondência. Avenida José Gabriel de Oliveira, nº 685 apto 1606, CEP:86047-360. ${ }^{2}$ Docente Departamento de Clínicas Veterinárias, UEL, Londrina, Paraná, Brasil. mzanutto@uel.br. Cx postal: 10.011.

${ }^{3}$ Docente Departamento de Clínicas Veterinárias, UEL, Londrina, Paraná, Brasil. maurolahm@gmail.com. Cx postal: 10.011.

${ }^{4}$ Docente Departamento de Clínicas Veterinárias, UEL, Londrina, Paraná, Brasil. asampaio@uel.br. Cx postal: 10.011. 
dulares a ulceradas, com prurido moderado a intenso e exsudativas (COSTA, 2012). Uma característica da afecção é a formação de 'kunkers' que macroscopicamente se apresentam como granulomas subcutâneos ulcerados preenchidos por material necrótico, amarelado, seco e friável (MENDOZA; AJELLO; MCGINNIS, 1996).

O diagnóstico precoce é importante assim como o diferencial de algumas doenças como a habronemose. É baseado no histórico, sinais clínicos e a partir de amostras de "kunkers" para a detecção do agente, detecção de anticorpos anti-P. insidiosum ou detecção do DNA do agente pela PCR, sendo que o diagnóstico histopatológico ou citológico também podem ajudar (SANTURIO et al., 2006b ; GAASTRA et al., 2010).

Várias formas de tratamento são descritas na literatura, como por exemplo, a imunoterapia utilizando a vacina Pitium-Vac, vacina desenvolvida pelo Laboratório de Pesquisa Micológicas (LAPEMI-UFSM) e Embrapa Pantanal, o uso de antibióticos como macrolídeos e tetraciclinas e antifúngicos como a anfotericina $\mathrm{B}$ associados ou não à excisão cirúrgica (DOS SANTOS et al, 2011).

A pitiose é uma doença de importante estudo, pois além dos gastos com o tratamento, a enfermidade pode levar à retirada do animal da atividade atlética temporária ou definitivamente. Além das possíveis complicações que podem ocorrer em decorrência da doença, que pode inclusive levar à morte do animal (MORAES et al, 2013).

O objetivo deste trabalho é realizar uma revisão bibliográfica abordando a pitiose, sua etiologia, epidemiologia, fisiopatogenia entre outros aspectos importantes para a compreensão da doença.

\section{Desenvolvimento}

\section{Aspectos Epidemiológicos}

O agente da doença, Pythium insidiosum, tem distribuição mundial, sendo relatado em países com clima tropical, subtropical e temperado, como Colômbia, Costa Rica, Venezuela e Brasil. No Brasil existem relatos nas regiões sul e centro-oeste, ocorrendo geralmente em áreas alagadiças, na época das chuvas ou em períodos úmidos (FREY JÚNIOR et al., 2007; ALEXOPOULOS; MIMS, 1996; LUIZ LEON; PERES, 2012).

A infecção é mais frequente em cães e animais de produção, sendo os equinos os mais acometidos e em humanos e felinos a doença é rara (MENDOZA; HERNANDEZ; AJELLO, 1993; PRASERTWITAYAKIJ et al., 2003; RAKICH; GROOTERS; TANG, 2005; SANTOS; SANTURIO; MARQUES, 2011; FERNANDES et al., 2012). Em estudos realizados em equinos infectados não se observou predisposição para raça, sexo ou idade dos animais (MENDOZA; ALFARO, 1986). Apesar da ocorrência de casos em humanos e animais o agente não possui potencial zoonótico ou transmissão por contato direto (COSTA et al, 2012).

A forma mais encontrada da pitiose em equinos é a cutânea, geralmente encontrada nas regiões distais dos membros, abdômen, tórax e região da mama, que são as regiões mais expostas ao ambiente onde se encontra o fungo e os animais podem apresentar mais de uma lesão, ou lesões em diferentes locais (Figura 1) (MENDOZA; ALFARO, 1986).
Além da forma cutânea, a pitiose pode apresentar-se também na forma subcutânea, vascular, ocular, e existem relatos de acometimento visceral nas espécies equina e canina (FERNANDEZ et al., 2012; LUIZ LEON; PERES, 2012; AMARAL et al, 2013).

Figura 1: Lesão causada por Pythium insidiosum em porção distal de membro de equino (A) e em região abdominal (B).

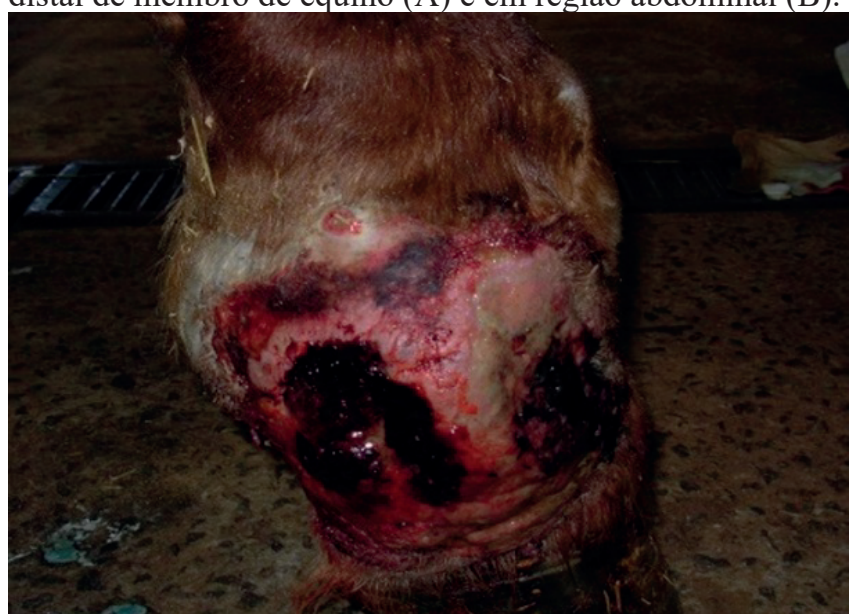

A

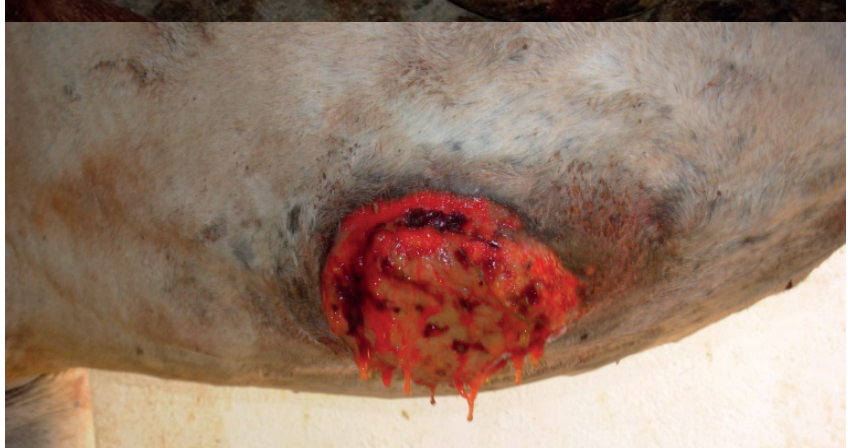

B

Fonte: Arquivo pessoal

\section{Etiologia e forma de trasmissão}

$\mathrm{O}$ agente causador da pitiose é um micro-organismo que pertence ao Reino Stramenopila, Classe Oomycetes, Ordem Pythiales, Família Pythiaceae, Gênero Pythium, espécie $P$. insidiosum (SANTURIO et al., 2006a). Não é considerado um verdadeiro fungo, pois sua parede não é composta de quitina e sim de celulose e $\beta$-glucanas, e sua membrana não contém ergosterol como a maioria dos fungos (ALEXOPOULOS; MIMS, 1996). O P. insidiosum tem sua taxa máxima de crescimento aos $37^{\circ} \mathrm{C}$ e este é inibido aos $40^{\circ} \mathrm{C}$ (DAVIS et al, 2006). Reproduz-se de forma assexuada produzindo zoósporos biflagelados, que ficam livres na água até encontrarem uma planta ou animal (possuem forte atração por pele e pelo de equinos, cabelo humano e gramíneas), onde irão se encistar através de um tubo germinativo e posteriormente formar grande quantidade de filamentos de hifas, que podem colonizar os tecidos cutâneo e subcutâneo, produzir lesões intestinais, acometer vasos sanguíneos e ossos do hospedeiro. O P. insidiosum pode se desenvolver em mais de um tipo 
de planta aquática e até em restos de plantas em meios aquáticos ou úmidos (MENDOZA; HERNANDEZ; AJELLO, 1993; LUIZ LEON; PERES, 2012; ZANETTE et al, 2013a; ZARO, 2013).

O animal adquire a infecção através de pequenas feridas, do contato com a água que contém os zoósporos e ainda, estudos sugerem a possibilidade de transmissão por mosquitos infectados (GAASTRA et al., 2010).

SinAIS CLÍNICOS

O principal sinal clínico da pitiose são lesões circulares, irregulares com um processo inflamatório e prurido intenso, desenvolvem-se lesões ulcerativas granulomatosas, com exsudato sanguinolento a sero-sanguinolento que ao corte apresenta tecido conjuntivo fibroso com trajetos fistulosos e um tecido necrótico chamados 'kunkers' que ao exame radiográfico (Figura 2) podem demonstrar áreas de radio-opacidade com calcificação (MENDOZA; HERNANDEZ; AJELLO, 1993; SALLIS; PEREIRA; RAFFI, 2003; SANTURIO et al., 2006a). Os kunkers são formações branco-amareladas formadas pela degranulação de eosinófilos sobre as hifas de $P$. insidiosum, podendo essas massas ter diferentes tamanhos (GAASTRA et al., 2010). As lesões possuem caráter progressivo podendo haver complicações como desenvolvimento de tecido de granulação exuberante, caquexia e até morte (SANTOS; SANTURIO; MARQUES, 2011). As extremidades distais dos membros, a região abdominal e peitoral dos equinos são os locais onde mais frequentemente se encontram as lesões causadas pelo agente (ALVAREZ; GARCIA; GARAY, 2010; SANTOS; SANTURIO; MARQUES, 2011; LUIZ LEON; PERES, 2012).

Figura 2: Radiografia de membro de equino com pitiose evidenciando a presença de 'kunkers' (setas brancas).

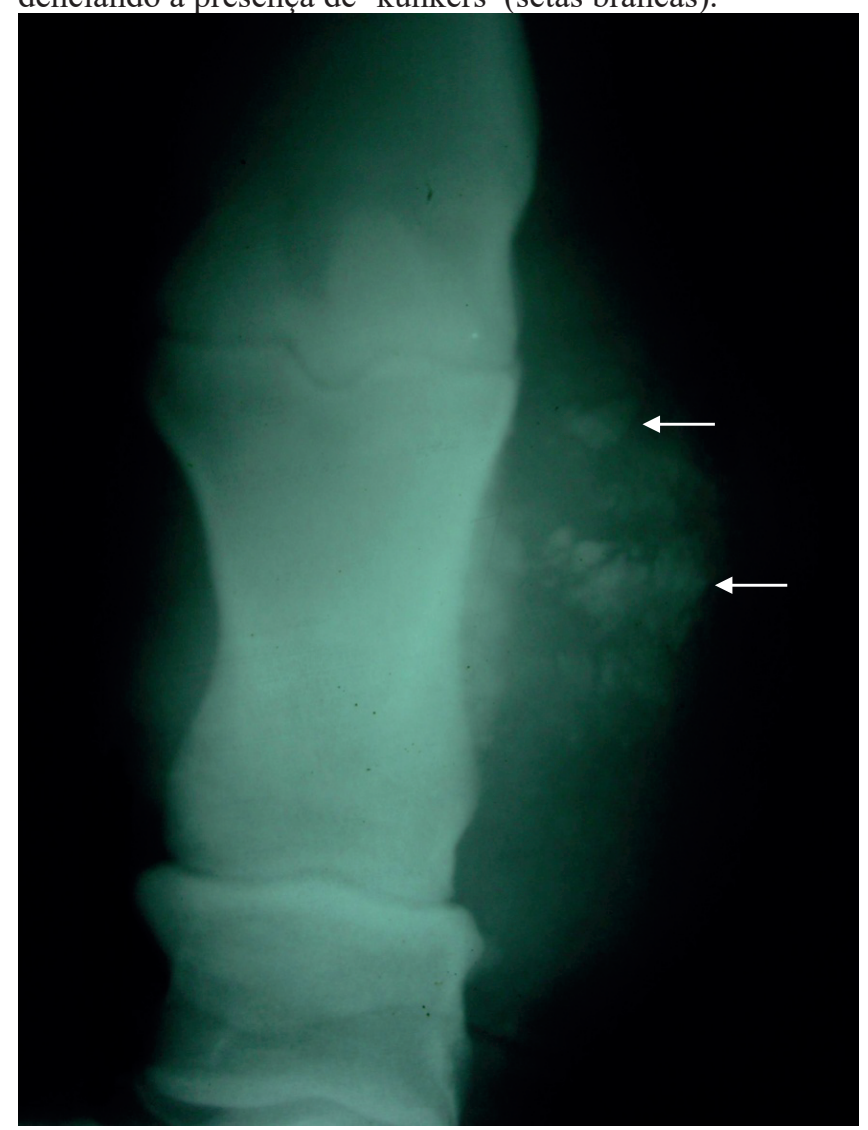

Fonte: Arquivo pessoal.
Os animais ainda podem apresentar emagrecimento progressivo, hipoproteinemia, linfadenomegalia e anemia, esta, possui correlação com o tamanho da lesão, pois já foi comprovado em estudo em coelhos que a patogenia da pitiose interfere no metabolismo do ferro no organismo (ZANETTE et al, 2013b). Em casos mais graves as lesões podem levar a danos no tecido ósseo e claudicação (MENDOZA; AJELLO; MCGINNIS, 1996).

\section{Diagnóstico}

O diagnóstico é baseado no histórico do animal, sinais clínicos, exame histopatológico, isolamento e identificação do agente e ainda técnicas sorológicas, por exemplo, imunodifusão, ELISA e imunohistoquímica e técnicas moleculares como a PCR (SANTURIO et al., 2006b).

$\mathrm{Na}$ anamnese, informações como o ambiente onde o animal vive, alimentação, rotina e evolução da ferida são importantes dados para conduzir o diagnóstico (VAZ, 2009).

É realizado o exame macroscópico da lesão observando a forma irregular, tecido de granulação ulcerado com uma cor branco amarelada e eventualmente áreas necróticas com a presença dos 'kunkers', e em seguida a colheita de amostra (Figura 3). Para a colheita é necessário ser realizada a limpeza e antissepsia da lesão, com possibilidade de sedação do animal e anestesia local, podem ser realizadas incisões para a retirada de amostras de tecidos e dos 'kunkers' (MÁRQUEZ et al, 2010).

Figura 3: Colheita de amostra da região da lesão para histopatológico com o uso de punch(A). Amostras colhidas para o exame $(\mathrm{B})$.

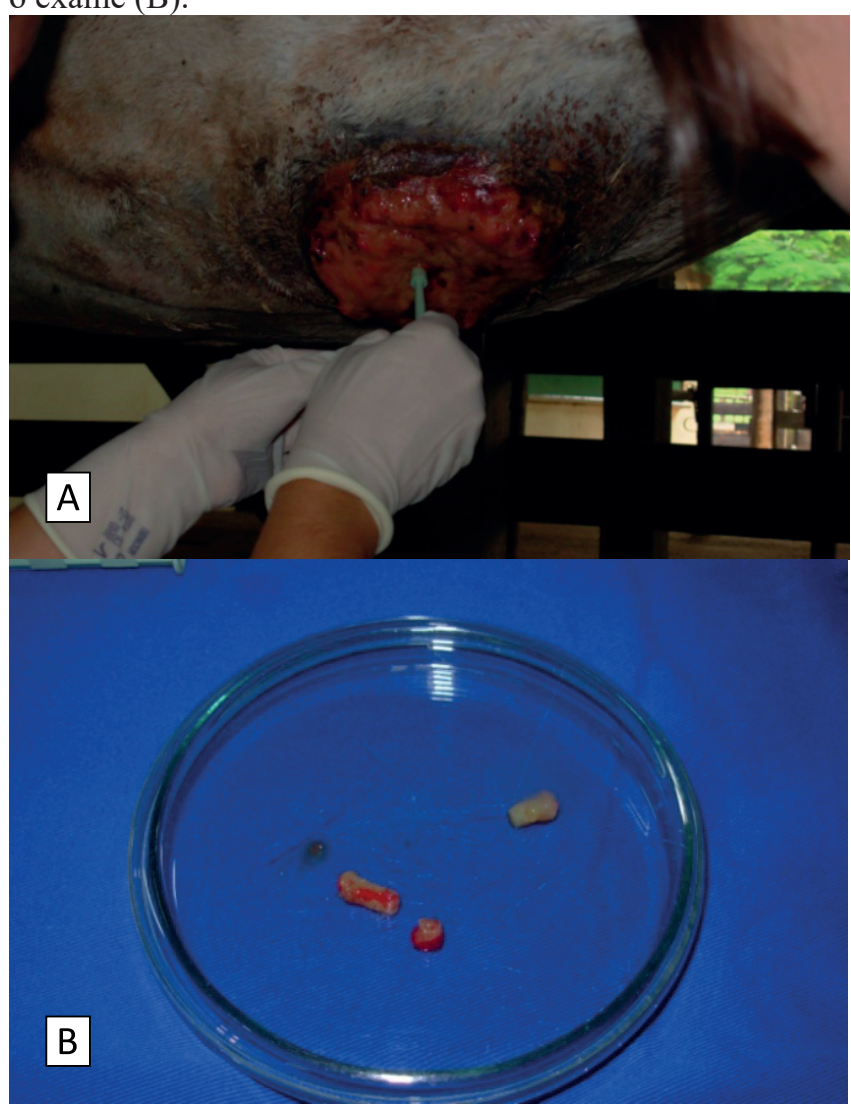

Fonte: Arquivo pessoal. 
As amostras podem ser fixadas em formalina a $10 \%$ tamponada por 24 horas, conservadas em álcool $70 \%$ e coradas pela coloração hematoxilina-eosina e Grocott para o exame histológico, o qual vai apresentar grave dermatite com infiltração de neutrófilos e eosinófilos, macrófagos e tecido fibroso na coloração hematoxilina-eosina, e na coloração de Grocott observam-se estruturas ramificadas ocasionalmente septadas de cor café, paredes lisas e paralelas no interior das áreas de necrose (PEDROSO et al., 2009; CARDONA; VARGAS; PERDOMO, 2012).

Outro método de identificação é a imunohistoquimica, um método que marca especificamente as hifas de $P$. insidiosum e possui como vantagem a possibilidade de ser utilizada em tecidos previamente fixados além de apresentar maior especificidade que o método de Grocott metanamina (REIS JR; NOGUEIRA, 2002; PEDROSO et al., 2009). A probabilidade de falsos negativos é baixa, pois as hifas $P$. insidiosum apresentam moléculas antigênicas específicas do reino Chromista, e estes não são encontrados nas hifas dos fungos zigomicetos (MENDOZA et al., 1997; REIS JR; NOGUEIRA, 2002).

O diagnóstico clinico das lesões associado à histopatologia com resultados sugestíveis de pitiose são métodos de diagnóstico confiáveis, e em conjunto com a imunohistoquimica pode ser confirmada a doença (DÓRIA, 2014).

A técnica de identificação por meio da técnica de ELISA foi descrito primeiramente por Mendoza et al., (1997), e em 2006, Santurio et al. descreveram a técnica de ELISA indireto para o diagnóstico da pitiose em equinos e coelhos, utilizando 72 soros de equinos sadios e 44 de equinos com pitiose confirmada e 48 amostras de coelhos saudáveis e 24 com pitiose. O estudo concluiu que o teste ELISA indireto para a pitiose possui alta especificidade e sensibilidade além da diminuição do tempo necessário para o diagnóstico (SANTURIO et al., 2006b).

Além da importância do diagnóstico precoce é importante também a diferenciação da pitiose de outras doenças como a habronemose, infecções fúngicas, tecido de granulação exuberante, carcinoma invasivo de células escamosas (GAASTRA et al., 2010).

\section{Tratamento e Prognóstico}

Por diferir da maioria dos fungos em suas características, como conter celulose e $\beta$-glucanas em sua parede e não conter o ergosterol em sua membrana plasmática, que é o componente atacado pelos antifúngicos, o tratamento para pitiose torna-se muitas vezes complicado (FOIL et al., 1996).

O sucesso do tratamento vai depender de inúmeros fatores como o tipo de tratamento, o tamanho e localização das lesões, tempo de evolução e estado geral do animal (KNOTTENBELT; PASCOE, 2003). Mosbah et al. (2012), realizaram o tratamento da pitiose em equinos no Egito com excisão cirúrgica nos animais com lesões recentes e de pequena extensão, que resultou em cura total sem complicações. A excisão cirúrgica pode ser associada ao tratamento local com perfusão regional intravenosa de anfotericina B, um antimicótico macrolídeo, que utilizado na dose e diluição adequada pode ser uma alternativa de tratamento eficaz para a pitiose em equinos, gerando poucas reações adversas e completa cicatrização, como possíveis complicações citadas o edema dos membros e inflamações no local da administração (DORIA, 2012).

Outra forma de tratamento utilizada é a imunoterapia. A vacina, Pitium-Vac, desenvolvida pelo Laboratório de Pesquisa Micológica (LAPEMI-UFSM) em conjunto com a Embrapa Pantanal, foi desenvolvida a partir de extratos de proteína de $P$. insidiosum e tem como objetivo a modificação da resposta imune do hospedeiro para desenvolver uma resposta adequada contra a doença. Estudos demonstraram que a imunoterapia não protege contra reinfecções, uma vez que animais previamente vacinados para pitiose voltaram a apresentar a infecção em outras partes do corpo, porém também responsivas à imunoterapia (SANTOS, 2009; LORETO et al., 2014).

A imunoterapia tem sido utilizada com sucesso em muitos casos no tratamento da pitiose (Figura 4), em equinos e pode ser utilizada associada ou não à excisão cirúrgica com resultados favoráveis, com boa aplicabilidade a campo, além do baixo custo (BACH et al., 2010; DOS SANTOS et al., 2011; SANTOS; SANTURIO; MARQUES, 2011).

Figura 4: Membro posterior de animal acometido de pitiose (A). Aspecto da mesma ferida 30 dias após início do tratamento imunoterápico $(\mathrm{B})$.

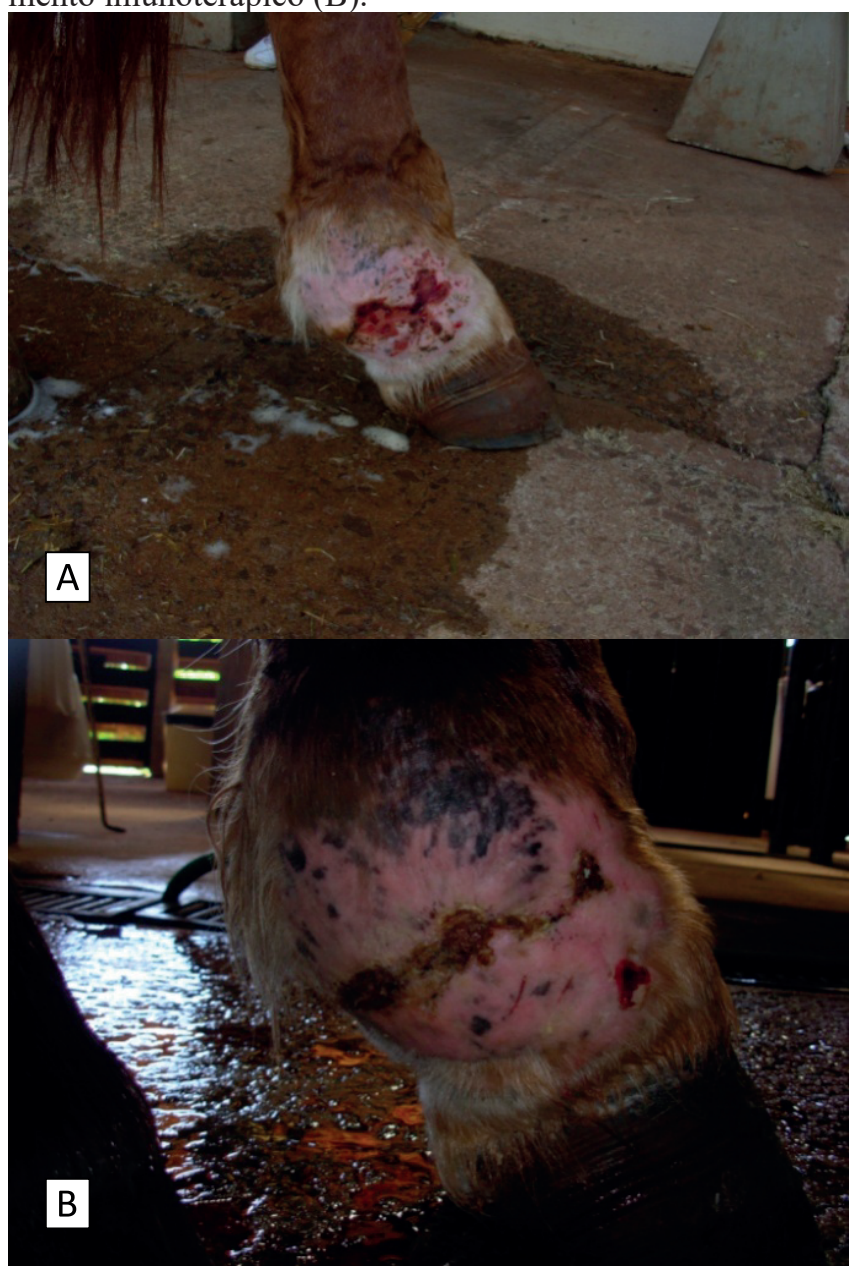

Fonte: Arquivo pessoal.

Foram realizados estudos in vitro utilizando macrolídeos e tetraciclina e sua ação sobre o $P$. insidiosum, e os resultados demonstraram que esses antibióticos possuem ação inibidora contra o agente, possivelmente pela inibição 
da síntese de proteínas e do transporte de aminoácidos, tornando esses antibióticos possíveis alternativas terapêuticas (LORETO et al, 2011). Recentemente, técnicas utillizando a terapia fotodinâmica tem sido introduzidas, tendo resultados favoráveis contra o P. insidiosum (PIRES, 2014).

\section{Impactos econômicos}

A pitiose pode causar grandes prejuízos para a agropecuária, pois seu tratamento pode se tornar complicado, economicamente dispendioso, além da possibilidade de ocorrer recidivas, complicações ou levar à morte do animal pela gravidade do caso ou pelo tratamento de forma errônea. Uma das formas de tratamento, que vem sendo amplamente utilizada é a vacina Pitium-vac, um imunoterápico desenvolvido no Brasil, adotada na maioria do país. Um estudo avaliou o impacto econômico causado pela sua adoção no tratamento da pitiose, revelando que o uso da vacina gerou uma renda adicional que variou de $\mathrm{R} \$ 461,01$ a $\mathrm{R} \$ 733,24$ por animal tratado em três anos com impacto positivo no agronegócio brasileiro. Além dos impactos ligados diretamente aos animais afetados é importante ressaltar também a importância dos estudos relacionados aos tratamentos e epidemiologia da doença (MACIEL et al., 2008; TOMICH et al., 2010; MORAES et al, 2014).

\section{Considerações Finais}

A pitiose é uma doença causada por um fungo oomiceto (Pythium insidiosum), distribuída mundialmente, que acomete diferentes espécies, inclusive o homem. A espécie equina é uma das mais acometidas, o que torna o estudo sobre a doença nessa espécie ainda mais importante uma vez que a doença pode causar prejuízos não só pelo custo com tratamentos, mas também pelas lesões causadas nos animais, que podem levar o animal a óbito. O diagnóstico é baseado nas informações da anamnese, sinais clínicos, histopatologia, e exames para isolamento e identificação do agente, como ELISA e PCR. O tratamento se difere de outras doenças fúngicas devido a diferenças das características do agente para outros fungos, como tratamento podemos citar a excisão cirúrgica e utilização de imunoterápicos. Por ser uma doença presente na clínica equina, pela dificuldade no tratamento e o risco que apresenta para os animais, merece atenção para que sejam realizados estudos futuros buscando opções mais avançadas de formas de diagnóstico e tratamento.

\section{Referências}

ALEXOPOULOS, C. J.; MIMS, C. W.; BLACKWELL, M. Introductory mycology, 4. ed. New York: John Wiley \& Sons, 1996. Cap. 23, p. 683-737.

ALVAREZ, J. C. ; GARCIA, L. R.; GARAY, O. V Pythiosis cutânea equina en córdoba, Colombia. Reporte de cinco casos. Revista Científica, v. 20, n. 6, p. 590-594, 2010.

AMARAL, L. A. et al. Relato de pitiose equina com envolvimento visceral. A Hora Veterinária, v. 32, n. 192, p. 32-35, mar/abr. 2013.
BACH, B. C. et al. Immunotherapy for pythiosis: Effect on NTPDase activity in lymphocytes of an experimental model. Biomedicine \& Pharmacotherapy, v. 64, n. 10, p. 718-722, 2010.

BIAVA, J. S. et al. Zigomicose em equinos - uma revisão. Revista Acadêmica, Curitiba, PR, v. 5, n. 3, p. 225-230, jul./set. 2007.

CARDONA, J.; VARGAS, M.; PERDOMO, S. Pythiosis cutânea equina en el departamento de Sucre, Colombia. REDVET, v. 13, n. 11, p. 1-7, 2012.

COSTA, L. R. R. Pythiosis. In: WILSON, D. A. Clinical Veterinary Advisor: the horse. 1. ed. St. Louis, Missouri: Elsievier Saunders, 2012, p. 485-487.

DAVIS, D. J. et al. Relationship between temperature optima and secreted protease activities of three Pythium species and pathogenicity toward plant and animal hosts. Mycological Research, v. 110, n. 1, p. 96-103, jan 2006.

DÓRIA, R. G. S. Treatment of Pythiosis in Equine Limbs Using Intravenous Regional Perfusion of Amphotericin B. Veterinary Surgery, v. 41, p. 759-765, 2012.

DÓRIA, R. G. S. Utilização da técnica de imunohistoquímica para confirmar casos de pitiose cutânea equina diagnosticados por meio de caracterização clínica e avaliação histopatológica. Arquivo Brasileiro de Medicina Veterinária e Zootecnia, v. 66, n. 1, p. 27-33, 2014.

DOS SANTOS, C. E. P. et al. Eficácia da imunoterapia no tratamento de pitiose facial em equino. Acta Scientiae Veterinariae, Santa Maria, v. 39, n. 1, p. 1-5, 2011.

FERNANDES, C. P. M. et al. Gastric pythiosis in a dog. Revista Iberoamericana de Micologia, v. 29, n. 4, p. 235237, 2012.

FOIL C.S. et al. Update on Pythiosis (Oomycosis). Proceedings of the North American Veterinary Conference, v. 10, p. 140-142, 1996.

FREY JR, F. et al. Pitiose equina na região sul do Brasil. Revista Portuguesa de Ciências Veterinárias, v. 102, p. 107-111, 2007.

GAASTRA, W. et al. Pythium insidiosum: An overview. Veterinary Microbiology, Amsterdam, v. 146, n. 1-2, p. $1-16,2010$.

KNOTTENBELT, D. C.; PASCOE, R. R. The integumentary system. In: Color atlas of diseases and disorders of the horse. WB Saunders, p. 257-74, 2003.

LORETO, E. S. et al. In vitro susceptibility of Pythium insidiosum to macrolides and tetracycline antibiotics.

Antimicrobial Agents and Chemoterapy, v. 55, n. 7, p. 3588-3590, jul. 2011. 
LORETO, E. S. et al. Update on pythiosis immunobiology and immunotherapy. World Journal of Immunology, v. 4 n. 2, p. 88-97, jul 2014.

LUIZ-LEON, J. J.; PEREZ, R. C. Pythiosis: Una patología emergente en Venezuela. Salus online, v. 15, n. 1, p. 79-94, abr. 2011.

MACIEL, I. C. F. et al. Pitiose fatal em eqüino tratado inicialmente para habronemose cutânea. Acta Scientiae Veterinariae, v. 36, n. 3, p. 293-297, 2008.

MÁRQUEZ, A. A et al. Descripción Anatomopatológica de Pitiosis Cutánea en Equinos. Revista de la Facultad de Ciencias Veterinarias, v. 51, n. 1. P. 37-42, 2010.

MENDOZA, L.; AJELLO, L.; MCGINNIS, M. R. Infections caused by the oomycetous pathogen Pythium insidiosum. Journal Medical and Veterinary Micology, Oxfordshire, v. 6, n.4, p. 151-164, 1996.

MENDOZA, L.; ALFARO, A. A. Equine pythiosis in Costa Rica: Report of 39 cases. Mycopathologia, v. 94, n. 2, p. 123-129, maio 1986.

MENDOZA, L.; HERNANDEZ, F.; AJELLO, L. Life cycle of the human and animal oomycete pathogen Pythium insidiosum. Journal of Clinical Microbiology, v. 31, n. 11, p. 2967-2973, nov. 1993

MENDOZA, L. et al. Serodiagnosis of human and animal pythiosis using an enzyme-linked immunosorbent assay. Clinical and diagnostic laboratory immunology, v. 4, n. 6, p. 715-718, 1997.

MORAES, A. S. et al. Impactos econômicos, sociais e ambientais de tecnologias da Embrapa Pantanal: Pitium$\operatorname{Vac} \AA$ : imunoterápico contra pitiose equina. Disponível em: <https://www.embrapa.br/busca-de-publicacoes/-/ publicacao/980716/impactos-economicos-sociais-eambientais-de-tecnologias-da-embrapa-pantanal-pitiumvac-imunoterapico-contra-pitiose-equina $>$. Acesso em 16 set. 2014

MOSBAH, E. et al. Diagnosis and surgical management of pythiosis in draft horses: report of 33 Cases in Egypt. Journal of Equine Veterinary Science, v. 32, n. 3, p. 164 $169,2012$.

PEDROSO, P. M. O. et al. Diagnóstico imuno-histoquímico de pitiose cutânea em equinos. Acta Scietiae Veterinariae, v. 37 , n. 1 , p. 49-52, 2009.

PIRES, L. et al. Photodynamic therapy in Pythium insidiosum - an in vitro study of the correlation of sensitizer localization and cell death. Plos One, v. 9, n. 1, p.1-8, 2014.

PRASERTWITAYAKIJ, N. et al. Human pythiosis, a rare cause of arteritis: case report and literature review. Seminars in Arthritis and Rheumatism, v. 33, n. 3, p. 204-214, dez. 2003.
RAKICH, P.; GROOTERS, A.; TANG, K.; Gastrointestinal pythiosis in two cats. Journal of Veterinary Diagnostic Investigation, v. 17, n. 3, p. 262-269, maio. 2005.

REIS JR, J.; NOGUEIRA, R. Estudo anatomopatológico e imunoistoquímico da pitiose em equinos naturalmente infectados. Arquivo Brasileiro de Medicina Veterinária e Zootecnia, v. 54, n. 4, p. 358-365, 2002.

SALLIS, E. S. V.; PEREIRA, D. I. B.; RAFFI, M. R. Pitiose cutânea em equinos: 14 casos. Ciência Rural, Santa Maria, v. 33, n. 5, p. 899-903, set/out. 2003.

SANTOS, C. Does Immunotherapy protect equines from reinfection by the oomycete Pythium insidiosum? Clinical and Vaccine Imunology, v. 18, n.8, p. 1397-1399, ago. 2009.

SANTOS, C. Contribuição ao estudo da pitiose cutânea equina em equideos do pantanal norte, Brasil. ARS Vet, Jaboticabal-SP, v. 27, n. 3, p. 134-140, 2011.

SANTOS, C.; SANTURIO, J.; MARQUES, C. Pitiose em animais de produção no Pantanal Matogrossense. Pesquisa Veterinária Brasileira, v. 31, n. 11, p. 1083-1089, 2011.

SANTURIO, J.M. et al. Pitiose: uma micose emergente. Acta Veterinary Science, Santa Maria, RS, v. 34, p. 1-14, out. 2006a.

SANTURIO, J. et al. Teste de ELISA indireto para o diagnóstico sorológico de pitiose. Pesquisa Veterinária Brasileira, v. 26, n. 1, p. 47-50, jan/mar 2006b.

TOMICH, T. R. et al. Impacto econômico decorrente do controle da pitiose equina empregando-se o imunoterápico Pitum-Vac. In: Embrapa Pantanal-Artigo em anais de congresso (ALICE). SIMPÓSIO SOBRE RECURSOS NATURAIS E SOCIOECONÔMICOS DO PANTANAL, 5., 2010, Corumbá, MS. Anais... Corumbá: Embrapa Pantanal: UFMS; Campinas: ICS do Brasil, 2010.

VAZ, B. B. U. et al. Pitiose nasal em equino. Medicina Veterinária, v. 3, n. 4, p. 27-32, Recife, out/dez 2009.

ZANETTE, R. A. et al. Enzymatic variability among Brazilian Pythium insidiosum isolates. Revista Iberoamericana de Micologia, v. 30, n. 4, p. 264-266, 2013a.

ZANETTE, R. A. et al. Insights into the pathophysiology of iron metabolism in Pythium insidiosum infections. Veterinary Microbiology, v. 162, p. 826-830, 2013 b.

ZARO, D. Pythium Insidiosum: revisão literária e relato de caso em equino. 2013. 47. Trabalho de conclusão de curso (graduação em medicina veterinária). Universidade federal do Rio Grande do Sul, Porto Alegre.

Recebido em: 20.12.2016 Aceito em: 18.09.2017 